\title{
Fine Needle Aspiration Cytology of Cervical Lymphadenopathy: Is There Anything Different At South Coastal Region of India?
}

\author{
Priya R, Dhananjay Kotasthane*, Vaishali Dhananjay Kotasthane and Koteeswaran G
}

Department of Pathology, Mahatma Gandhi Medical college and Research Institute, pillaiyarkuppam, Pondicherry (India)

\section{ABSTRACT}

Background: Cervical lymphadenopathy is one of the commonest clinical presentations of the patients in all age groups. FNAC is simple, inexpensive and minimally invasive procedure that can be used as an outpatient procedure for diagnosing lymphadenopathy cases.

Aims and Objective: To assess the various causes of cervical lymphadenopathy through FNAC and to see the distribution of various lesions with respect to age and gender and to correlate with histopathological findings.

Materials and Methods: The present Analytical cross-sectional study was conducted in the Department of Pathology, Mahatma Gandhi Medical College and Hospital, Pondicherry from January 2010 to July 2016.FNAC was done by standard procedure. All the slides were reviewed and diagnosis was rendered. Cytology findings were compared with histopathological diagnosis where-ever excision biopsy was done.

Results: A total of 411 patients were included in the present study. Overall, female preponderance was seen. In benign non-neoplastic lesions, peak occurrence was seen in the 3rd decade, whereas it was 7 th decade in metastatic lesions. Benign lymphadenopathies were diagnosed in $75.1 \%$ of cases, majority being chronic reactive lymphadenitis(34.6\%) followed by granulomatous lymphadenitis(30\%). The proportion of granulomatous lymphadenitis was more in our study as compared to other studies $(\mathrm{p}<0.0001)$.In neoplastic lesions, majority $(88 \%)$ were metastatic deposits. In metastatic lesions, higher proportion of metastatic thyroid carcinoma (13.9\%) was seen which was statistically significant $(\mathrm{p}<0.0001)$ as compared to other studies. Unpaired t test was used to prove statistical significance. Cyto-histopathology correlation was done in 54 cases and FNAC showed sensitivity of $97 \%$,specificity $95 \%$ and diagnostic accuracy of $96 \%$.

Conclusion: FNAC is safe, simple, rapid, minimally invasive and inexpensive procedure to diagnosis cervical lymphadenopathy with high sensitivity, specificity and diagnostic accuracy. Higher frequency of granulomatous lesions was seen in non-neoplastic cases. In neoplastic lesions, metastatic thyroid carcinoma showed higher frequency in our study conducted at iodine sufficient south coastal region of India.

Keywords: Fine Needle Aspiration Cytology, Lymph Node, Histopathology

\section{Introduction}

Cervical lymphadenopathy is one of the commonest clinical presentations of all age groups attending the outpatient department. ${ }^{[1]}$ The various etiologies for cervical lymphadenopathy are broadly categorized as microbial infections \& their breakdown products, malignancies, iatrogenic conditions, autoimmune disorders. ${ }^{[2]}$ The general approach to cervical lymphadenopathy includes: detailed clinical evaluation, fine needle aspiration cytology and open biopsy. ${ }^{[3]}$ FNAC has become an important diagnostic tool for initial and rapid diagnosis and management of patients having lymphadenopathy, owing to its simplicity, reliability, early availability of results and it, being a minimally invasive procedure. It is a primary method for diagnosing whether lymphadenopathy is due to reactive, infective or metastatic causes, thereby avoiding unnecessary excisional biopsy and aiding in rapid onset of therapy. ${ }^{[3,4]}$
The cytomorphological features obtained through FNAC correlates well with histological appearance. Thus, FNAC is considered as an ideal method for diagnosing the nature of lesions. ${ }^{[5,6]}$ The diagnosis of metastatic tumor to the lymph node by cytomorphological pattern is highly reliable and it is a sole indicative procedure for evaluating primary tumor in case of the occult primary. ${ }^{[7,8,9]}$ In case of non-neoplastic lesions, the varied morphological patterns can mimic the other reactive conditions and it can lead to multiple differential diagnosis..$^{[10,11,12]}$ In case of primary lymphoid malignancies, FNAC is mainly used to assess the tumor staging and to recognize the residual and recurrence of lymphoid malignancy.

The aim of the study was to describe different cytological lesions of cervical lymphnode in context with age, sex and mode of presentation and to compare these findings with histopathological diagnosis to calculate sensitivity, specificity and diagnostic accuracy. 


\section{Materials and Methods}

The present Analytical study on 411 patients with cervical lymphadenopathy was done at the Department of Pathology, Mahatma Gandhi Medical College and Research Institute over a period of 6.5 years from January 2010 to July 2016 after obtaining clearance from institutional Human ethics committee.

Aspirations from All cervical lymph nodes were included in the study i.e submental, submandibular, (level Ia, Ib) and posterior triangle including supraclavicular lymphnodes (level V). The relevant clinical details were noted from the accompanying requisition forms and/or from the patient case records. Clinical data including age, gender, clinical diagnosis, site and duration, consistency and any organ involvement like hepatosplenomegaly were noted. The cytology slides of all cases were examined to determine the cyto-morphological features. Cytology findings were compared with histopathological diagnosis wherever excision biopsy was done. The efficacy of FNAC was tested by using statistical test like Sensitivity, Specificity, Diagnostic accuracy, Positive predictive value and Negative predictive value after cyto-histopathology correlation. Unpaired $\mathrm{t}$ test was applied to compare our findings with other studies and $\mathrm{p}$ value $<0.05$ was considered as significant.

\section{Results}

Total 411 patients of all age groups with cervical lymphadenopathy were included in this study and the peak occurrence was observed in $3^{\text {rd }}$ decade of life accounting for $23.6 \%$ (97 cases).We observed that non-neoplastic lesions were common in the $3^{\text {rd }}$ decade with female preponderance, in contrast with metastatic lesions which were more common in the $7^{\text {th }}$ decade with male preponderance.

In the present study, out of 411 cases, majority of the patients presented with left sided cervical lymphadenopathy with frequency of $55.7 \%$ and right sided involvement in $40.4 \%$. Bilateral involvement was seen in $3.9 \%$ cases. Out of total 411 cases, non-neoplastic lesions were more common accounting for $75.1 \%$, followed by neoplastic $22 \%$ and non-diagnostic $2.9 \%$.In non-neoplastic lesions, chronic reactive lymphadenitis was found to be the most common pathological lesion(34.6\%) followed by granulomatous lesion(30\%)[Fig1]. Distribution of remaining non-neoplastic cases was shown in Table 1.Ninetycytology cases showed neoplastic lesions and were further grouped into metastatic, Hodgkin's and nonHodgkin's lymphomas. Out of these, metastatic lesions were more common with an occurrence of $87.7 \%$. The occurrence of metastatic Adenocarcinoma and Squamous cell carcinoma showed equal frequency in our study with
62 cases $(39.2 \%)$ each. Metastasis occurred from primary carcinoma in breast, stomach, colon, rectum, and lung.[Fig $2 \& 3]$ The occurrence of metastatic thyroid carcinoma in our study was $13.92 \%$.[Fig 4] The youngest patient in our study was 5 year girl presented with nodular enlargement of thyroid with multiple group of cervical lymph node enlargement over a period of 6 months. In 3 cases, ultrasonography revealed multiple cystic areas admixed with solid areas which were diagnosed as metastasis from papillary carcinoma of thyroid, correlating with cytological diagnosis. In our study, metastatic malignant melanoma was reported in one case. Clinically, a 65 year old male patient presented with $4 \times 3 \mathrm{~cm}$, raised, ulcerated wound present in the right plantar aspect of the foot for a duration of six months with multiple groups of lymph node involvement. On aspiration, highly cellular smear shows scattered and few clusters of polygonal shaped cells with eosinophilic cytoplasm with vesicular nuclei with prominent nucleoli. Both intracellular and extracellular melanin pigmentation is seen. Background shows Melanophage and melanin.[Fig 5]

Cytologically, 5 cases were diagnosed as Non-Hodgkin's lymphoma. The age group ranged from 32 to 60 years with male preponderance. Cytologically, 6 cases were diagnosed as Hodgkin's lymphoma, majority of patients were in $2^{\text {nd }}$ and $3^{\text {rd }}$ decade with male preponderance. Clinically, all patients presented with cervical lymph node enlargement. Two patients presented with splenomegaly. Microscopically, 4 cases showed Classic Reed Sternberg cell and two cases showed mononuclear cells morphology.

Correlation of Cytological Diagnosis with Histopathology: In this study period, 411 cases of cervical lymphnode were referred to Department of pathology for aspiration.Out of these, 12 smears were inadequate or non-diagnostic, hence exclude from further evaluation. Table 2 showed that for 90 cytologically diagnosed neoplastic lesions, histopathology was available in 33 cases. Similarly, for 309 non-neoplastic FNAC lesions, histopathology was available in 21 cases only as non-surgical treatment is usually preferred for non-neoplastic lesions. Thus, for 399 cytology cases, histopathology was available in 54 cases.[Table 2]

From Table 2,metastatic (26 cases) and Hodgkin's lymphoma (6 cases) showed 100\% cyto-histopathology correlation, whereas in NHL, 3 out of 4 showed correlation with histopathological diagnosis of small cell lymphoma in two cases, one showed Diffuse Large cell lymphoma(DLCL)but remaining one case turned out to be granulomatous lymphadenitis accounting for false positivity. Similarly, in 21 non-neoplastic lesions, cyto- 
histopathology correlation was seen in 20 cases and one case of granulomatous lesion showed features of NonHodgkin's lymphoma on histology accounting for false negativity. Based on these results, sensitivity, specificity, positive predictive value, negative predictive value and diagnostic accuracy of FNAC to diagnose cervical lymphnode lesions were calculated and was found to be $97 \%, 95 \%, 97 \%, 95 \%, 97 \%$ and $96 \%$ respectively.

Table 1: Age wise distribution of non -neoplastic lesions of cervical lymph Node.

\begin{tabular}{|l|c|c|c|c|c|c|c|c|c|c|}
\hline & $\mathbf{0 1 - 1 0}$ & $\mathbf{1 1 - 2 0}$ & $\mathbf{2 1 - 3 0}$ & $\mathbf{3 1 - 4 0}$ & $\mathbf{4 1 - 5 0}$ & $\mathbf{5 1 - 6 0}$ & $\mathbf{6 1 - 7 0}$ & $\mathbf{7 1 - 8 0}$ & TOTAL (n=309) & Percentage \% \\
\hline $\begin{array}{l}\text { Chronic nonspecific reactive } \\
\text { lymphadenitis }\end{array}$ & 18 & 28 & 29 & 12 & 7 & 9 & 4 & 12 & 106 & 34.64 \\
\hline Granulomatous lymphadenitis & 6 & 21 & 28 & 16 & 12 & 7 & 3 & 1 & 94 & 30.04 \\
\hline Suppurative lymphadenitis & 3 & 3 & 6 & 11 & 2 & - & - & - & 26 & 8.41 \\
\hline Necrotizing lymphadenitis & 1 & 2 & 3 & 1 & 1 & - & - & - & 8 & 2.58 \\
\hline Tuberculous lymphadenitis & 4 & 15 & 24 & 13 & 4 & 8 & 2 & 2 & 72 & 23.33 \\
\hline Others(RDD) & - & - & 2 & - & 1 & - & - & - & 3 & 0.97 \\
\hline Percentage \% & 10 & 22.3 & 30 & 17.1 & 8.7 & 7.8 & 2.9 & 4.8 & - & $100 \%$ \\
\hline
\end{tabular}

Table 2: Cyto-Histo Correlation of Cervical Lymph Node Lesion(n=54).

\begin{tabular}{|c|c|c|c|c|}
\hline \multirow{3}{*}{$\begin{array}{l}\text { FNAC DIAGNOSIS(N=399) } \\
\text { Neoplastic }(\mathrm{N}=33)\end{array}$} & \multicolumn{4}{|c|}{ HPE (N=54) } \\
\hline & \multicolumn{3}{|c|}{ NeOplastic(N=33) } & \multirow{2}{*}{ Non -Neoplastic $(\mathrm{N}=\mathbf{2 1})$} \\
\hline & Metastasis $(\mathrm{N}=26)$ & $\mathrm{HL}(\mathrm{N}=3)$ & NHL $(\mathrm{N}=4)$ & \\
\hline Metastasis $(\mathrm{N}=79)$ & 26 & - & - & - \\
\hline $\mathrm{HL}(\mathrm{N}=6)$ & - & 3 & - & - \\
\hline $\mathrm{NHL}(\mathrm{N}=5)$ & - & - & 3 & 1 \\
\hline Non-Neoplastic $(\mathrm{N}=309)$ & \multicolumn{2}{|l|}{ - } & 1 & 20 \\
\hline
\end{tabular}

Table 3: Comparison of Distribution of different pathological subtypes of metastasis with other studies.

\begin{tabular}{|l|c|c|c|c|}
\hline FNAC of metastatic LN & Ghartimagar D et al. ${ }^{26}$ & Rathod K et al & Pavithra et al & Present study $^{20}$ \\
\hline Adenocarcinoma & $67 \%$ & $2 \%$ & $9.37 \%$ & $39.24 \%$ \\
\hline Squamous cell carcinoma & $39.24 \%$ & $96 \%$ & $56 \%$ & $39.24 \%$ \\
\hline Thyroid carcinoma & $2 \%$ & - & $4.68 \%$ & $13.94 \%$ \\
\hline $\begin{array}{l}\text { Poorly differentiated } \\
\text { carcinoma }\end{array}$ & - & $1 \%$ & $25 \%$ & $5.06 \%$ \\
\hline Malignant melanoma & $2 \%$ & $1 \%$ & $1.56 \%$ & $1.26 \%$ \\
\hline
\end{tabular}

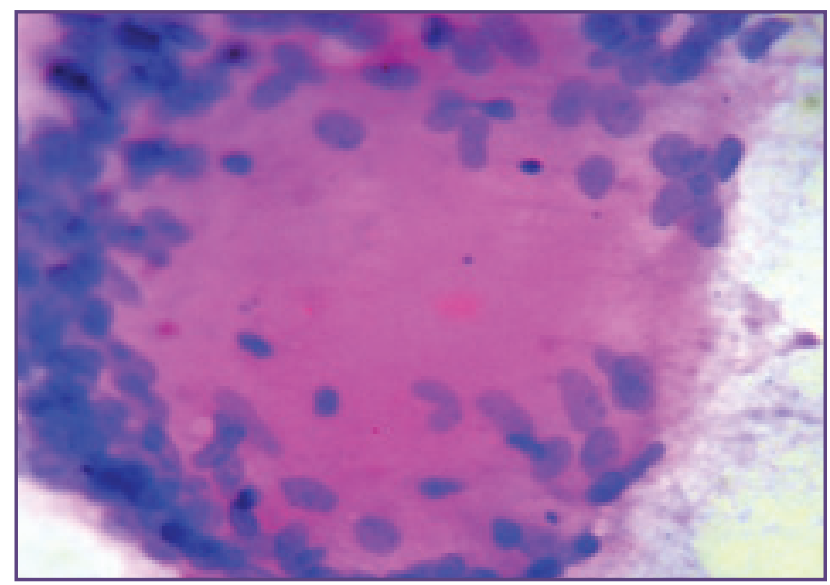

Fig. 1: Tuberculous lymphadenitis showing caseous necrosis and granuloma (H\&E 40x).

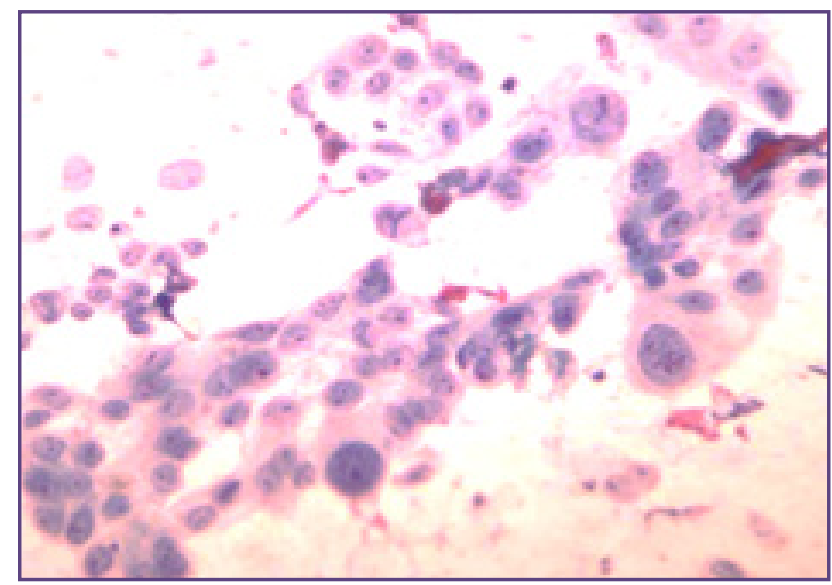

Fig. 2: Aspirate shows dyscohesive clusters of cells with scant cytoplasm and pleomorphic nuclei with prominent nucleoli in Metastatic Infiltrating DuctalCarcinoma of breast (H\& E Stain 40x). 


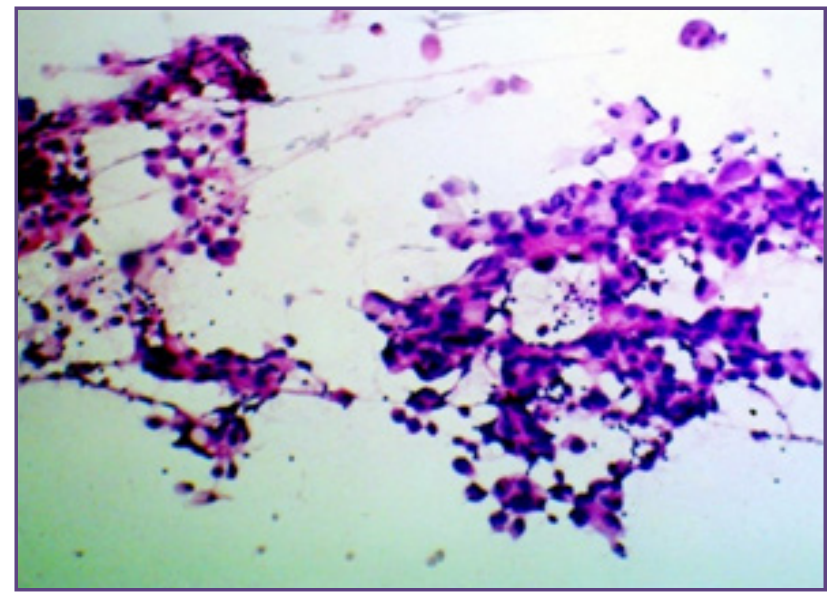

Fig. 3: Cytology smear showing metastatic adenocarcinoma (H\&E 10x).

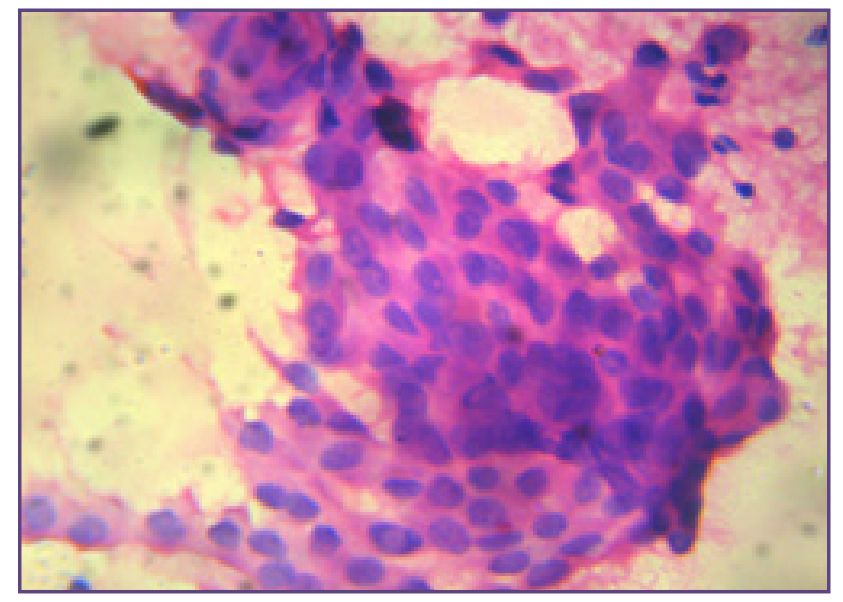

Fig. 4: Aspirate shows papillary fragment containing cells with large nuclei havingintranuclear inclusion in metastatic papillary carcinoma thyroid (H \& E 10x).

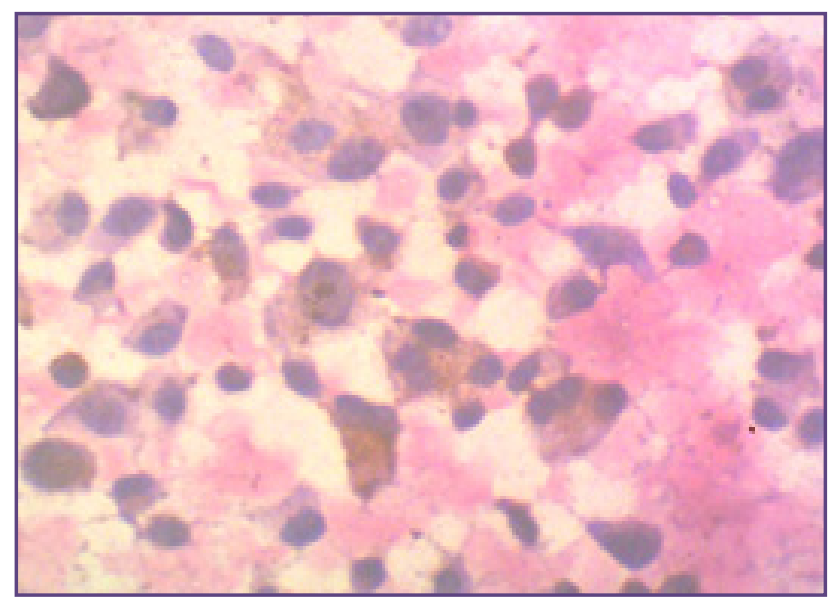

Fig. 5: Aspirate shows dispersed melanin laden pleomorphic cells in metastatic malignant melanoma(H \&E 40x).

\section{Discussion}

Among the different groups of lymph nodes, cervical group is easy to access by FNAC and therefore it plays a major role in establishing rapid diagnosis. FNAC also plays important role in diagnosing the etiology of cervical lymph node enlargement due to early availability of results, better patient compliance and minimal trauma. ${ }^{[13]}$ The diagnosis obtained through FNAC very well correlates with histopathological diagnosis after excision biopsy. ${ }^{[14]}$

The gender distribution of cases in our study showed clear female preponderance with a male: female ratio of $1: 1.7$ in adulthood. Similar findings were noted by other authors.

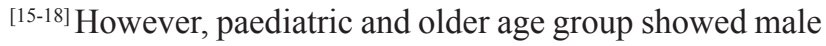
predominance in our study.

In the present study, we observed that non- neoplastic lesions were common in the $3^{\text {rd }}$ decade whereas neoplastic lesions were more common in $6^{\text {th }}$ to $7^{\text {th }}$ decade. Findings of our study showed correlation with the study conducted by Dukare et al, Pavithra et al and Kumar et al. ${ }^{[19,20,21]}$ In our study, left sided cervical lymph node lesions were most commonly involved in both neoplastic and nonneoplastic lesions with an frequency of $55.7 \%$, whereas right sided lesions accounted for $40.4 \%$.Similar findings were noted by Attaullah et al. ${ }^{[17]}$ In the current study, we observed that non-neoplastic lesions was the most common cause of cervical lymph node enlargement accounting for $74.5 \%$. In other studies, similar findings were observed with frequency of non-neoplastic lesion ranging from 70 to $90 \%{ }^{[19,22,23]}$

Among non-neoplastic lesions, reactive lymphadenitis was the most common pattern with an occurrence of $34.6 \%$, which showed mild preponderance over granulomatous lymphadenitis (30.04\%).Other studies also showed majority cases belonging to reactive lymphadenitis ranging from $50 \%$ to $70 \%$. Our study showed $63 \%$ cases of granulomatous 
lymphadenitis, which was higher than other studies, which reported these cases ranging from 25 to $30 \%{ }^{[13,23,24,]}$. This difference was found to be statistically significant using unpaired t test with $\mathrm{p}$ value $<0.0001$.In the present study, one cytologically diagnosed granulomatous lymphadenitis turned out to be Non-Hodgkin's Lymphoma on histopathology accounting for false negativity probably due to non availability of architecture on cytology or sinus histiocytes aspirated on smear appeared as ill formed granulomas.

In the neoplastic lesions, metastatic lesions accounted for $87.78 \%$.Similar findings were noted by other authors. ${ }^{[19,20]}$ Among metastatic lesions, both adenocarcinoma and squamous cell carcinoma has the occurrence rate of about $39.4 \%$ each, followed by thyroid carcinoma $13.9 \%$. Most of the Indian studies observed that, metastatic lesion in cervical lymph node was mainly due to squamous cell carcinoma followed by adenocarcinoma. ${ }^{[20,25]}$ But, in our study, adenocarcinoma showed the same frequency with that of squamous cell carcinoma(SCC). As SCC is common in head and neck region and we get less number of cases of this region in our hospital, metastatic adenocarcinoma in supraclavicular lymphnode showed equal proportion with SCC as compared to other studies. Ghartimagar et al also reported higher frequency of metastatic adenocarcinoma over squamous cell carcinoma in their study. ${ }^{[26]}$ Table 3]. In our study, Metastatic thyroid carcinoma (predominantly papillary carcinoma) showed higher frequency of $13.9 \%$ as compared to other studies which showed frequency ranging from 2 to $5 \%$. ${ }^{[20,26]}$ [Table 3].Unpaired t test showed significant statistical difference with $\mathrm{p}$ value $<0.0001$. This could be due to higher iodinated salt intake because of our coastal region as documented in literature thatincreased iodine supplementation increases risk for thyroid malignancy, particularly Papillary thyroid carcinoma(PTC). ${ }^{[27]}$ Similar findings were noted by Indian studies mentioning environmental conditions and dietary habits i.e diet rich in fish may be contributing factor for wide spread distribution of PTC occurring in coastal areas of Tamilnadu, Andhra Pradesh\& Kerala which are iodine rich and the iodine content of soil is thought to modify the development of these cancers. ${ }^{[28]}$ Previous studies conducted in our hospital also showed higher frequency of thyroid carcinomas predominantly papillary carcinomas which needs further molecular studies. ${ }^{[29]}$

In neoplastic lesions, apart from metastasis, Hodgkin's and Non-Hodgkin's Lymphoma showed frequency of $6.6 \%$ and $5.5 \%$ respectively. Similar findings were observed by other authors. ${ }^{[21,23,30]}$ In our study, one cytologically diagnosed Non-Hodgkin's lymphoma turned out to be granulomatous lymphadenitis accounting for false positive diagnosis probably due to inadequate sampling or sampling predominantly of germinal centre centroblastic cells or large atypical cell appearance due to drying artifact because of late fixation. Thus, cytology has limitations in diagnosing Lymphomas due to non-availability of complete architecture for complete assessment. Also, diagnostic accuracy is said to be lower for lymphomas compared to metastatic malignancy. ${ }^{[31]}$

In our study, the overall diagnostic accuracy of FNAC in diagnosing cervical lymph node lesions was 97\% with sensitivity $97 \%$, specificity $95 \%$, positive and negative predictive value to be $97 \%$ and $95 \%$ respectively which was comparable with other studies. In other studies, sensitivity ranged from $90 \%$ to $99 \%$ and specificity from 70 to $100 \%$. $^{[15,32,33]}$

\section{Conclusion}

Fine needle aspiration cytology offers a simple, safe, quick and minimally invasive technique which can be performed as an outpatient department procedure for rapid diagnosis of neoplastic and non-neoplastic lesions of cervical lymph nodes for better patient care management. Our study showed high sensitivity, specificity and diagnostic accuracy, thus making it reliable investigation in further management of cervical lymphnode lesions. Also, significant findings in our study were higher frequency of granulomatous lymphadenitis in non-neoplastic lesions and higher occurrence of metastatic thyroid carcinoma in this rural tertiary healthcare centre located at iodine sufficient eastern coastal region of South India.

\section{References}

1. Hirachand S, Lakhey M, Akhter J, Thapa B. Evaluation of fine needle aspiration cytology of lymph nodes in Kathmandu Medical College, Teaching hospital. Kathmandu Univ Med J. 2009; 7(2):139-42.

2. Bazemore AW, Smucker DR. Lymphadenopathy and malignancy. American family physician.2002 Dec;66(11):2103-110.

3. Young JA. Fine needle aspiration cytopathology. J of Pathol. 1993 Jan;169(1):109-114.

4. Keith VE, Harsharan SK, Jerald GZ. Fine needle aspiration biopsy of lymph nodes in the modern era: reactive lymphadenopathies. Pathol Case Rev 2007; 12(1):27-35.

5. Howlett DC, Harper B, Quante M, Berresford A, Morley M, Grant J, Ramesar K, Barnes S. Diagnostic adequacy and accuracy of fine needle aspiration cytology in neck lump assessment: results from a regional cancer network over a one year period. J Lary \& Otol. 2007 Jun 1; 121(06):571-79.

6. Kline TS. Handbook of Fine Needle Aspiration Biopsy Cytology. 2nded. New York: Churchill Livingstone; 1988.p.492.

7. Kollur SM, El Hag IB. Fine needle aspiration cytology of metastatic nasopharyngeal carcinoma in cervical lymph nodes: comparison with metastatic squamous cell carcinoma and Hodgkin' and Non Hodgkin' lymphoma. DiagCytopathol $2003 ; 28: 18-22$. 
8. Miliauskas J. Diagnostic accuracy of FNAC of Lymph node lesions. In: Orell SR, Sterrett GF, editors. Fine needle aspiration cytology.5thed.New York: Churchill Livingstone;2012.p.85-86.

9. Al-Mulhim AS, Al-Ghamdi AM, Al-Marzooq YM, Hashish HM, Mohammad HA, Ali AM, Gharib IA. The role of fine needle aspiration cytology and imprint cytology in cervical lymphadenopathy. Saudi Med J.2004;25(7):862-5.

10. Haque MA, Talukder SI. Evaluation of fine needle aspiration cytology of lymph node in Mymensingh. Mymensingh Med J. 2003 Jan;12(1):33-35.

11. Gupta AK, Nayar M, Chandra M. Reliability and Limitations of Fine Needle aspiration cytology of lymphadenopathies. An analysis of 1,261 cases. ActaCytol 1991; 35: 777-83.

12. Ferrer R. Lymphadenopathy: differential diagnosis and evaluation. Am FamlPhysician 1998;58:1313-20.

13. Khajuria R, Goswami KC, Singh K, Dubey VK. Pattern of Lymphadenopathy on Fine Needle Aspiration Cytology in Jammu. JK Sci J of Cytology. 2006; July-Sep;8 (3) : 157- 59.

14. Steel BL, Schwartz MR, Ramzy I. Fine needle aspiration biopsy in the diagnosis of lymphadenopathy in 1103 patients. Role, limitations and analysis of diagnostic pitfalls. ActaCytol. 1995;39(1):76-81.

15. Nesreen H. Hafez, Neveen S. Tahoun. Reliability of fine needle aspiration cytology (FNAC) as a diagnostic tool in cases of cervical lymphadenopathy. J Egyptian Nat Cancer Inst 2011;23: 105-114

16. Sharma P, Rana S, Gill MK, Singh P, Satarkar RN, Kalhan S. Spectrum of lymph node lesions on cytology in rural Haryana: a retrospective analysis. International J Res Med Sci. 2015 May;3(5):1125-30.

17. Attaullah M, Shah W, Pervez SN, Khan S, Jehan S, Rahim S. cytomorphological pattern of superficial lymphadenopathy. Gomal Journal of Medical Sciences. 2014 Oct 1; 12(4):197-200.

18. Nidhi P, Sapna P, Shalini M and Kumud G. FNAC in tuberculous lymphadenitis- Experience from a tertiary level referral centre. Indian Journal of tuberculosis. 2011 jul; 58(3): 102-107.

19. Dukare SR, Jadhav DS, Gaikwad AL, Ranka SN, Kale PB, D'Costa G. Fine needle aspiration cytology of cervical lymphadenopathy - a study of 510 cases. Asian J Sci Technol. 2014 sep;5(9):537-40.

20. Pavithra P, Geetha JP. Role of fine needle aspiration cytology in the evaluation of the spectrum of lymph node lesions. Int J Pharm Bio Sci. 2014;5(4):377-84.
21. Kumar H, Chandanwale SS, Gore CR, Buch AC, Satav $\mathrm{VH}$, Pagaro PM. Role of fine needle aspiration cytology in assessment of cervical lymphadenopathy. Med J DY PatilUniv 2013;6:400-4.

22. Tanteo M, Garcia R.Clinical profile and histopathologic diagnoses of childhood peripheral lymphadenopathy: an MMC experience. Paed Infect Dis Soc. Phillipines. 2011;12(2):67-74.

23. Singh N, Singh A, Chauhan R, Singh P, Verma N. Fine needle aspiration cytology in evaluation of lymphadenopathy in pediatric age group: our experience at tertiary care centre. International Journal of Contemporary Medical Research. 2016;3(5):1347-51.

24. Sibanda EN, StanczukG. Lymph node pathology in Zimbabwe: a review of 2194 specimens. Quart J Med.1993;86:811-17.

25. Rathod KM, Shah SA. A Study of Metastatic Lesion of Lymph Node by Fine Needle Aspiration Cytology. Nat J Community Med.2012; 3(4):708-10.

26. Ghartimagar D, Ghosh A, Ranabhat S, Shrestha MK, Narasimhan R, Talwar OP., Utility of fine needle aspiration cytology in metastatic lymph nodes. Journal of Pathology of Nepal. 2011; 1:92-5.

27. Levi F, Vecchia CL, Randriamiharisoa A. Cancer mortality in Switzerland 1989. SozPreventimed. 1991; 36:112-126.

28. Sepuri M, Das B. Spectrum of Thyroid carcinoma in coastal Andhra Pradesh. Aretrospectivestudy. J. Evid Based Med. Healthcare.2016; 3(71): 3840-44.

29. Bharathidhasan I, Goneppanavar M, Dhaka RS. Changing trends in the incidence of thyroid lesions in coastal regions of south india. Int j Health Sci Res. 2015; 5(6):134-141.

30. Wilkinson AR, Mahore SD, Maimoon SA. FNAC in the diagnosis of lymph node malignancies: A simple and sensitive tool. Indian $\mathbf{J}$ Med PaediatrOncol 2012; $33: 21-24$

31. Cardillo MR. Fine needle aspiration cytology of superficial lymph nodes. Diagnostic cytopathology. 1989;5(2):166-73.

32. Babu GS, Ramesh G, Kashyap B, Suneela S, Hiremath SS, Murgud S. Cytohistopathological evaluation of the cervical lymph nodes by fine needle aspiration cytology. Journal of Cranio-Maxillary Diseases.2014 ;3(2):101-5.

33. Paliwal U K,Nigam $S$ K. Diagnostic accuracy of fine needle aspiration cytology in Cervical Lymph Nodes with Histopathological correlation. Journal of Evolution of Medical and Dental Sciences. 2013; (32): 5936-42.

*Corresponding author:

Dr Dhananjay Shrikant Kotasthane, Mahatma Gandhi Medical college and Research Institute, pillaiyarkuppam, Pondicherry-607402 (India)

Phone: +91 9092096244

Email: dskotasthane@gmail.com

Date of Submission : 07.04.2017

Date of Acceptance : 29.04.2017

Financial or other Competing Interests: None. 